\title{
Assessment and Guidelines to Improve Eco-efficiency and Indoor Comfort at University of Passo Fundo, Brazil
}

\author{
Marcos Antonio Leite Frandoloso and Luciana Londero Brandli \\ Faculty of Engineering and Architecture, University of Passo Fundo, Passo Fundo 99052-900, Brazil
}

\begin{abstract}
The paper deals with the energy and indoor comfort on buildings of UPF (University of Passo Fundo), located in southern Brazil, in order to improve the eco-efficiency concepts in the university's building stock, reinforcing its responsibility towards sustainable development. The factors that affect thermal performance and the energy consumption of two case studies were identified, including the general characteristics of the envelope and the indoor conditions. The simulations with DesignBuilder software compare the energy and thermal performance of both cases: those results allow the identification of their positive and negative aspects, as well as making a co-relation with the students' sensations of comfort — obtained through PMV (predicted mean vote). The research indicates that it will be possible to improve eco-efficiency of existing and new buildings and campuses by retrofitting and upgrading it with regard to better indoor conditions that really correspond to climate conditions (hot and humid summers, and cold and damp winters), using passive strategies for heating and cooling and at the same time to improve rational use of natural resources and to reduce the environmental impact. Probably, giving comfortable conditions to the users will increase energy consumption, but there is a potential reduction of lighting and equipment that could minimize this impact.
\end{abstract}

Key words: Comfort energy efficiency, eco-efficiency, indoor comfort, university buildings, building retrofitting.

\section{Introduction}

The main role of universities is remarkable as well as their responsibility in preparing students for a more conscious and responsible professional future through knowledge and practical experience. They also have to be an example of concrete actions in order to achieve the principles of a sustainable society in a collaborative and responsible way by involving the entire university community in the imperative process of changing procedures and habits.

Various factors contribute to the process of evaluation of the level of adherence to concepts of sustainability within these areas. Kibert [1] refers to eco-efficiency, which includes the analysis of environmental impact and costs as factors of administration efficiency evaluation of institutions or companies. The author quotes the WBCSD (World

Corresponding author: Marcos Antonio Leite Frandoloso, Ph.D. candidate, research fields: renewable energy, eco-efficiency, university buildings, energy simulation and thermal performance. E-mail: frandoloso@upf.br.
Business Council on Sustainable Development), which defines seven elaborated elements to achieve eco-efficiency applied to goods and services: reducing the material requirements, reducing energy intensity, reducing toxic dispersion, enhancing materials recyclability, maximizing sustainable use of renewable resources, extending product durability and increasing the service intensity.

On the other hand, many authors have been discussing within interdisciplinary teams and also exchanging their experiences in order to accelerate the rate at educational institutions to foster and underpin the values, knowledge and actions to help their students transform society from unsustainable to sustainable patterns [2].

Frandoloso et al. [3] present that being efficient means reaching the proposed objectives. In this way, the attainment of energy efficiency takes place when the objectives are obtained by equally employing the least amount of resources possible. In other words, a building which is efficient in terms of energy should 
carry out all its activities with the lowest possible consumption of electricity and in a broader manner, all the raw materials it uses on all phases of its lifespan: resources on planning embodied energy of materials and construction systems, use and operation and refurbishment. The study also links the eco-efficiency of the user's requirements to reach an ideal indoor comfort.

Braungart and McDonough [4] consider the eco-efficient building by one that "is a big energy saver". But even, it should achieve a more complex design, being a "building that celebrates a range of cultural and natural pleasure - sun, light, air, nature, even food - in order to enhance the lives of the people who work there".

The higher education institutions can be compared to small cities, according to Frandoloso et al. [5], exhibiting in many cases complex infra-structures for their operation, which demand natural resources and generate environmental impact. In the case of UPF (University of Passo Fundo), for example, in August 2009 , the energy consumption was more than 314,000 $\mathrm{kWh}$, corresponding to approximately 3,000 residencies with four inhabitants or, similarly, to a town of 12,000 inhabitants.

The main goal of this work is to evaluate the energy and thermal performance of the building stock of the University of Passo Fundo, Rio Grande do Sul, and their interrelation with indoor users' comfort. Then, the aim is to propose guidelines to include or to increase eco-efficiency in the planning of university buildings and campuses.

These guidelines can then be incorporated within an institutional plan of environmental management to include sustainable development within the areas of administration and teaching, embracing these principles in all daily activities (graduation, research, extension and administration), following the principles of an EMS (Environmental Management System) of ISO 14.001 and EnMS (Energy Management System) of ISO 50001.
According to Ferreira et al. [6], the implementation of EMS is a holistic and integrated way to tackle environmental impacts that can be extremely valuable to improve eco-efficiency of university and promote sustainable learning.

\section{Method}

In order to analyse the thermal and energy output of the university buildings, energy auditing methodology was adopted, the same that was used in the park constructed by the UPC (Polytechnic University of Catalonia) [7-9], which made it possible to identify each building in relation to the different sources of energy and their respective uses.

The energy audit adopted in this research identifies and evaluates the buildings and system characteristics regarding the energy sources. The study's premise is that the energy consumption is related to three main factors: the energy demand (building location and building shell); the performance and efficiency of systems and installations; and the management of use and occupation (intensity and area-time distribution).

The analysis is based on two sources of information: the "static" data are related to the building location (outdoor and indoor conditions), building characteristics (architecture and construction), systems and infrastructure and energy resources. On the other hand, the "dynamic" data were obtained by modelling the occupied area, the number of users and the kind of activities together with their energy performance through an automatic control of energy consumption.

For the application of this methodology at the University of Passo Fundo, a characterization study [3] was initially developed in Campus 1, the main UPF campus with 341 ha, where the current use of energy was identified. In accordance with the building stock, two buildings were selected: the FEAR (Faculty of Engineering and Architecture). These buildings are representative of the diverse construction typologies in Campus 1: the G1 building, administrative and teaching block of Faculty of Engineering and 
Architecture-Fig. 1, and the L1 building with laboratories and classrooms and the FEAR and CEPA (Centre of Research in Agriculture)-Fig. 2. Two rooms from each building were selected, located at the opposite orientation.

The real conditions of the buildings were noted concurrently through record cards and temperature and humidity measuring devices (Data-loggers Testo, models 175-H2 e 175-T1), analogical energy gauges and software (SmartGateM-Gestal). The comparative analyses of the thermal advantages were obtained by applying the software DesignBuilder [10].

The evaluation of the standards of students' comfort had adopted the Fanger's PMV (predicted mean vote) [11] and Fanger and Toftun [12], using averages of the internal and external environment variables (average radiant temperature, temperature, humidity and relative air speed) and the global temperature.

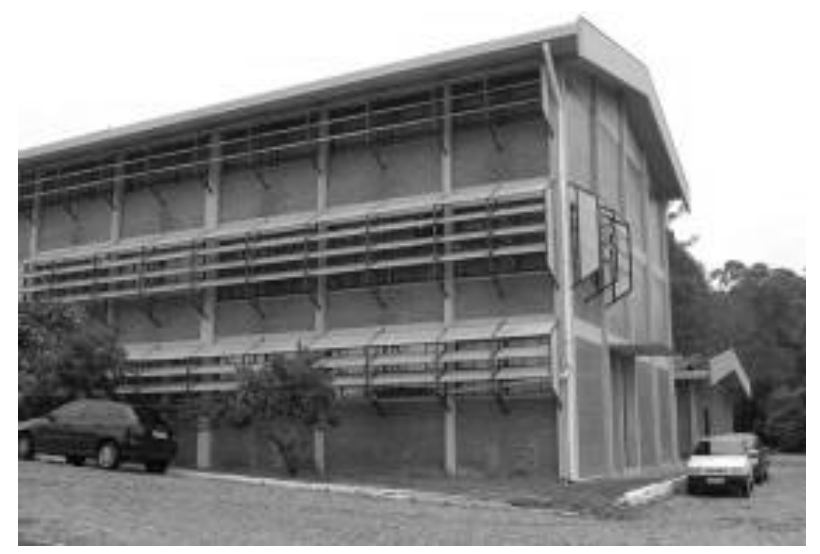

Fig. 1 G1 building — north facade.

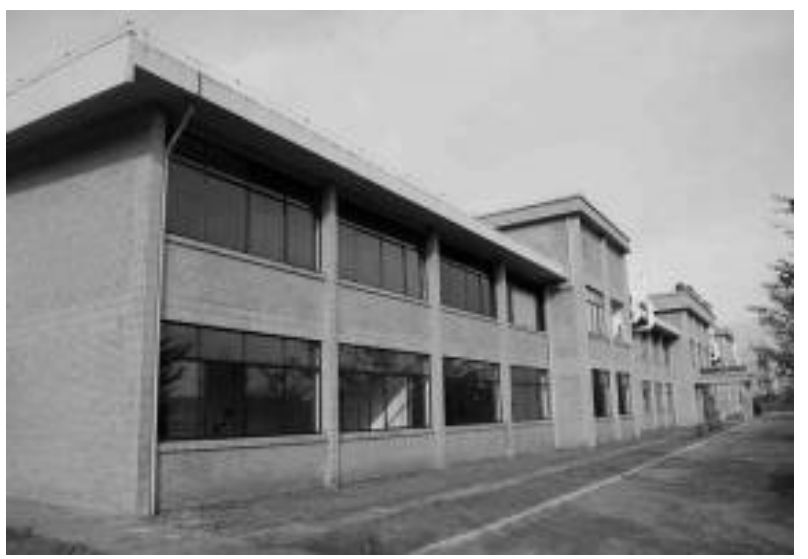

Fig. 2 L1 building-north facade.
Then, a questionnaire was applied to students of four classrooms, located in both buildings, in different periods of day and year, in order to identify their opinion about comfort classified in the ASHRAE's (American Society of Heating, Refrigerating and Air-Conditioning Engineers) Bedford scale [13].

\section{UPF and the Energy Resources}

The UPF is a multi-campus university, located in southern Brazil. The main campus occupies a peripheral zone of the city, the building park is around $110,000 \mathrm{~m}^{2}$, receiving a population of around 22,000 users (including students, teachers and staff) with several impacts on the neighborhood context and mobility.

The climatic conditions in Passo Fundo indicate a warm summer and cold winter, with a subtropical climate (Csa) by the Köppen classification [14]. These characteristics indicate the need for improvement of passive solar strategies for cooling and heating, as can be applied using Givoni's psychometric chart shown in Fig. 3.

In previous studies $[3,5]$, it was noted that within the environmental activities of UPF, besides another actions, energy consumption management of the campuses was considered, such as the installation of a group generator.

When the comparison between energy consumption and constructed area was observed (Table 1), the correspondence increased from $43 \mathrm{kWh} / \mathrm{m}^{2}$ (2004) to $51.42 \mathrm{kWh} / \mathrm{m}^{2}$ (2010). In 2009, the energy consumption increased $24.15 \%$, due to the expansion of computerization in all administrative and academic areas and, of particular significance, the increase of the use of air conditioning in the laboratories. This increase in energy consumption was correspondent to the increase in costs of approximately $60 \%$, which was seen to occur for the period of differentiation of subsidies from the energy supplier.

The energy consumption on Campus I corresponds to around $85 \%$ of the total consumption of UPF, indicating the relevance of a study of tools for control 


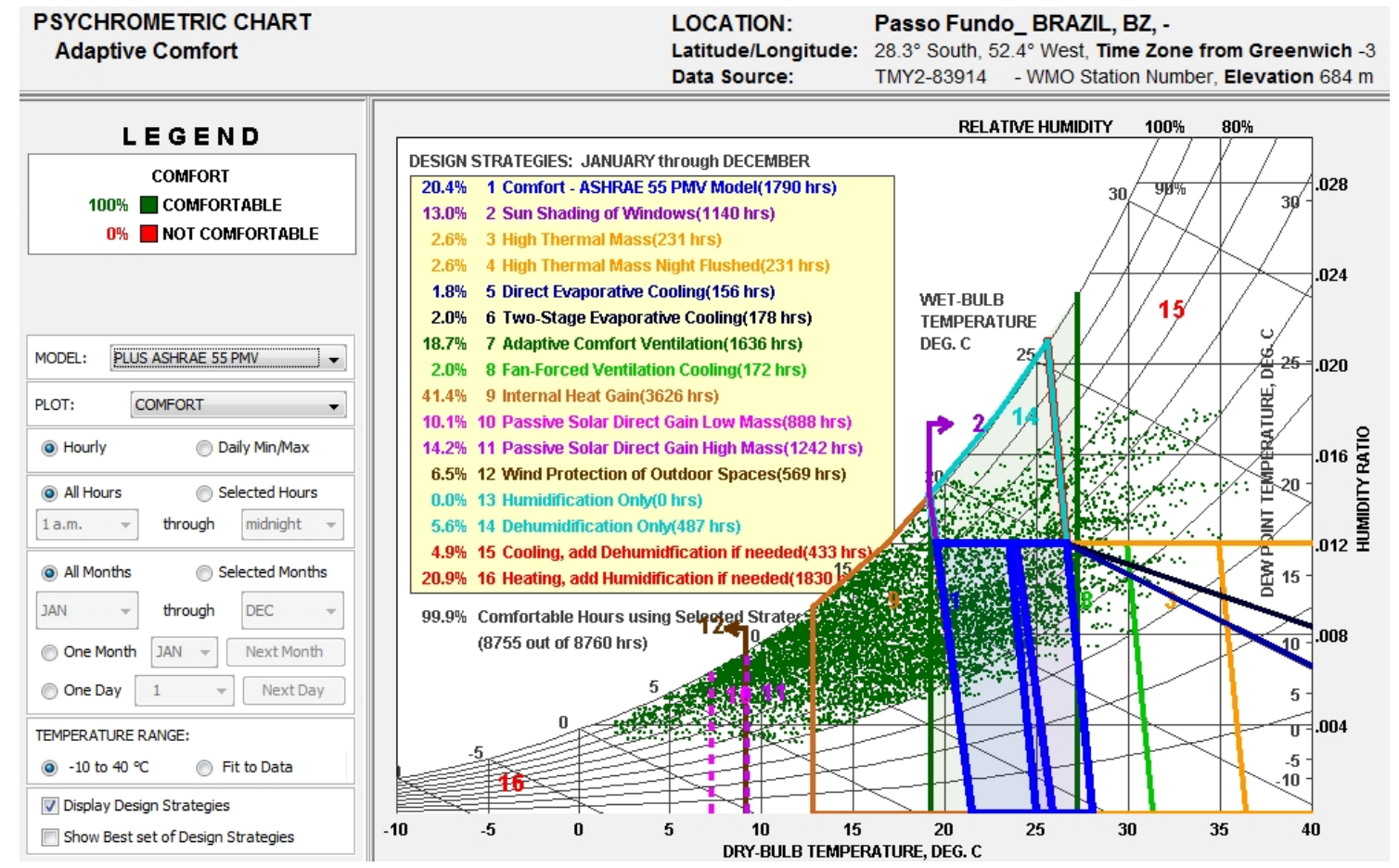

Fig. 3 Givoni's psychrometric chart to Passo Fundo by Climate Consultant [15].

Table 1 Evolution of construction area, energy consumption and costs (2004-2010).

\begin{tabular}{lrcr}
\hline Year & $\begin{array}{l}\text { Constructed } \\
\text { area }\left(\mathrm{m}^{2}\right)\end{array}$ & $\begin{array}{l}\text { Energy } \\
\text { consumption } \\
(\mathrm{GWh})\end{array}$ & $\begin{array}{l}\text { Costs } \\
\text { (thousand } \\
\mathrm{R} \$)\end{array}$ \\
\hline 2004 & $88,987.99$ & 3.91 & $1,557.56$ \\
2005 & $90,735.15$ & 3.98 & $1,912.87$ \\
$2005 / 2004(\%)$ & 1.96 & 1.70 & 22.81 \\
2006 & $99,071.34$ & 3.69 & $1,314.78$ \\
$2006 / 2005(\%)$ & 9.19 & -7.20 & -31.27 \\
2007 & $99,147.84$ & 4.42 & $1,439.72$ \\
$2007 / 2006(\%)$ & 0.08 & 19.68 & 9.50 \\
2008 & $103,293.84$ & 4.42 & $1,384.08$ \\
$2008 / 2007(\%)$ & 4.18 & 0.02 & -3.86 \\
2009 & $108,104.47$ & 5.49 & $2,214.30$ \\
$2009 / 2008(\%)$ & 4.66 & 24.15 & 59.98 \\
2010 & $109,675.24$ & 5.63 & $2,231.39$ \\
$2010 / 2009(\%)$ & 1.45 & 2.71 & -3.74 \\
\hline
\end{tabular}

and energy management which, as a consequence, would bring financial control.

It should also be mentioned that, until June 2009, energy consumption control was centralised, there being no division into units or isolated buildings. From this moment, a decentralization programme was set up (SmartGateM-Gestal), with the installation of equipment in each of the energy consumption units, which made it possible to control and monitor online, permitting the detection of specific problems. Monitoring can take place when the pre-established limits are exceeded and it is also possible to disconnect these installations or activate the equipment using the independent generator.

\section{Energy Performance}

The first stage of the research was the collection of static data, in order to know about the general characteristics of the buildings and their internal spaces, presenting their construction and architectonic characteristics [3].

The other step of the evaluation was to compile dynamic data obtained by the energy consumption monitoring for different uses and subsequent area use and occupations. According to this, equipment reaches more than $65 \%$ of energy use at L1, due to the high power degree in engineering laboratories and in the CEPA, specifically concerning the quality control of foodstuffs such as milk and other products of animal origin. These commodities, aside from demanding high power equipment, require internal temperature 


\section{Assessment and Guidelines to Improve Eco-efficiency and Indoor Comfort at University of Passo Fundo, Brazil}

control of the atmosphere in building L1. On the other hand, a small percentage in relation to lighting is related to the fact that the building is of more recent construction, using more efficient lighting devices (32 W).

Regarding the G1 building, the Information Technology Laboratory of FEAR implies that there is around $56 \%$ of power because of the equipments. Also, the building is of an older construction, still using high energy consuming lamps with low efficiency output $(110 \mathrm{~W})$, which results in a total of $11.41 \%$.

In both buildings, the areas with air conditioning are basically restricted to some laboratories which require temperature control, which corresponds to $29.17 \%$ in L1 and only $12.72 \%$ in G1. This results in energy consumption below the thermal demand which is really necessary to find the ideal conditions of comfort, when compared with the analysis of the thermal output.

For the dynamic data, it means the variables in accordance with time, the uses and occupation of each space of both buildings were identified, showing a theoretical number of users of 799 (G1) and 645 (L1), based on maximum capacity of classrooms by class groups and practical laboratories (information technology and classes) and the real occupation of the specialized laboratories in building L1.

The occupation diagnosis of the L1 building shows that the greatest rate of occupation is focused in the evening period because of the types of courses that use the classrooms and this exact same pattern of occupation is observed in the following semesters. In the daytime period, especially in the morning, the main use is by the CEPA laboratories, which represent external services from the university (SARLE-laboratory that analyses the quality of milk, for example), with equipment that is in permanent function.

Fig. 4 shows the monthly energy consumption at G1 and L1 buildings, where the occupation patters represent a relevant impact.

\section{Thermal Performance}

G1 was built using the original construction system (single masonry walls and expanded polystyrene

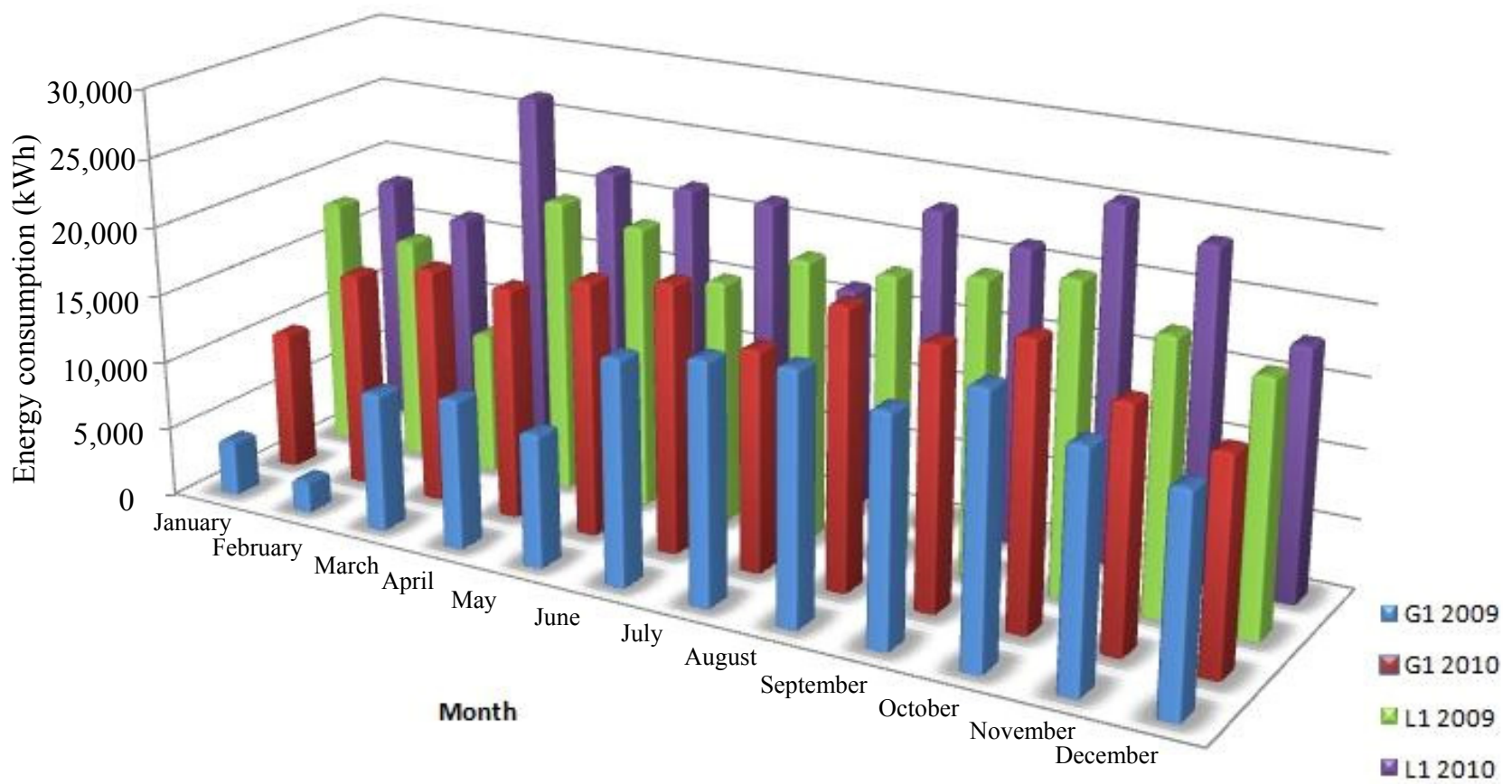

Fig. 4 Comparative energy consumption (2009-2010) of G1 and L1 buildings. 
ceiling in the upper floor). The L1 was built in the most recent typology with double brick walls and concrete ceiling [3]. In spite of almost the same construction characteristics, using the software DesignBuilder was calculated using the envelope properties with a $U=1.255 \mathrm{~W} / \mathrm{m}^{2} \cdot \mathrm{K}$ in G1 and $U=$ $1.105 \mathrm{~W} / \mathrm{m}^{2} \cdot \mathrm{K}$ in $\mathrm{L} 1$. Both thermal properties for walls when compared with the precepts of NBR 15575 [16] are below $2.50 \mathrm{~W} / \mathrm{m}^{2} \cdot \mathrm{K}$, the minimal thermal transmittance of the external walls indicated to the Bioclimatic Zone Z2, in accordance with the Brazilian Classification for Buildings and Construction Normative.

On the other hand, typological architectonic characteristics, solar orientation and protection are distinct, as can be seen in Figs. 1 and 2, especially due to the fact that, in building G1, solar protectors are present in the openings on the north and south sides. Besides, L1 does not possess protection systems except for the application of blinds and/or internal shutters in some of the windows or, in cases of emergency, paper fixed onto the windows to control the entrance of solar radiation and dazzling from the sun, as shown in Fig. 5.

The indoor conditions were collected in two rooms from each building: meat laboratory (L1) and the architecture department office (G1) which are orientated towards the north, and the practice laboratory (L1) and the environmental engineering department (G1) towards the south, with none of them possessing artificial conditioning.

In accordance with the indoor temperature measurements and relative humidity (Table 2), the maximum internal temperature recorded during the set period (2010) was $40.3{ }^{\circ} \mathrm{C}$ at meat laboratory (L1) which occurred at December 26, while the maximum external temperature reached $29.2{ }^{\circ} \mathrm{C}$ with a minimum of $15^{\circ} \mathrm{C}$. This temperature is above the upper limit recommended for acceptable condition in still air for people living in developing countries by Givoni [17] from $20^{\circ} \mathrm{C}$ to $29^{\circ} \mathrm{C}$ in summer.
For the cold periods, the measurements make the environmental engineering department (G1) the minimum indoor temperature which reaches $9.7{ }^{\circ} \mathrm{C}$ (outdoor temperature). It means below $18{ }^{\circ} \mathrm{C}$ by Givoni's [17] suggestion for winter (from $18^{\circ} \mathrm{C}$ to 27 $\left.{ }^{\circ} \mathrm{C}\right)$.

The preliminary simulation of energy and thermal performance by DesignBuilder confirms that the intense thermal gains are closely related with the constructive and occupational architectonic typology and the conditions of solar protection.

According to the DesignBuilder simulations, although in building G1, $67.61 \%$ is relative to the gains of the equipment ( $32.68 \%$ by the computers), $24.9 \%$ by solar radiation and $7.36 \%$ by occupation. In building L1, 34.19\% of thermal gains are by solar radiation, with other factors presenting similar results between them, despite a greater potency of equipment

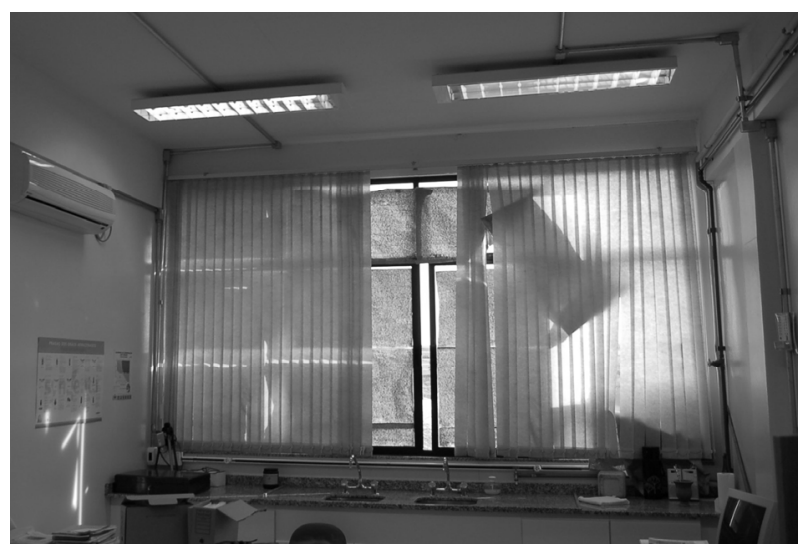

Fig. 5 "Alternative" solution for controlling solar radiation-north facade of $L 1$.

Table 2 Indoor conditions measurement.

\begin{tabular}{|c|c|c|c|c|c|}
\hline Room & $\begin{array}{l}\text { Indoor } \\
\text { conditions } \\
\end{array}$ & Min. & Day & Max. & Day \\
\hline \multirow{2}{*}{$\begin{array}{l}\text { G1 architecture } \\
\text { department }(\mathrm{N})\end{array}$} & RH (\%) & 20.0 & $\begin{array}{l}\text { December } \\
9\end{array}$ & 87.1 & March 22 \\
\hline & $\begin{array}{l}\text { Temperature } \\
\left({ }^{\circ} \mathrm{C}\right)\end{array}$ & 10.8 & July 21 & 36.7 & February 5 \\
\hline $\begin{array}{l}\text { G1 } \\
\text { environmental } \\
\text { engineering } \\
\text { department (S) }\end{array}$ & $\begin{array}{l}\text { Temperature } \\
\left({ }^{\circ} \mathrm{C}\right)\end{array}$ & 9.7 & July 16 & 33.9 & February 7 \\
\hline \multirow{2}{*}{$\begin{array}{l}\text { L1 meat } \\
\text { laboratory }(\mathrm{N})\end{array}$} & RH (\%) & 20.2 & July 13 & 84.7 & July 19 \\
\hline & $\begin{array}{l}\text { Temperature } \\
\left({ }^{\circ} \mathrm{C}\right)\end{array}$ & 13.4 & July 20 & 39.0 & April 3 \\
\hline $\begin{array}{l}\text { L1 practice } \\
\text { laboratory }(\mathrm{S})\end{array}$ & $\begin{array}{l}\text { Temperature } \\
\left({ }^{\circ} \mathrm{C}\right)\end{array}$ & 10.5 & August 4 & 40.3 & $\begin{array}{l}\text { December } \\
26\end{array}$ \\
\hline
\end{tabular}


$(61.86 \%)$. The comparison between the thermal benefits is presented in Fig. 6 .

\section{Indoor Comfort Performance}

The prediction model of thermal comfort for building users as well as the evaluation of thermal acceptance of internal environments is a subject normalized through ISO 7730 pattern [18]. The PMV or analytic sensation of thermal comfort was obtained from the model through the thermal balance between man and the environment, where the generation of heat by the organism due to the performance of an activity must be dissipated in the same rate to the environment, through the mechanisms of thermal exchanges, meaning convection, radiation, evaporation and conduction.

In order to evaluate the users, perception about their education environment, some questionnaires were applied, demanding their feelings with the temperature and humidity variables. Also, they were questioned about their clothes, which identify the proprieties and, finally, to calculate [19] the PPD (predicted percentage of people dissatisfied with their thermal environment).

For instance, with the application of questionnaires for users in sedentary occupation at the practice laboratory-L1, adopting Fanger's PMV methodology [11] and the Bedford scale [13], Fig. 7 shows that, in relation to the indoor, the condition is 100\%: $54.55 \%$ presented a sensation of little heat $(+1)$, $27.27 \%$ with heat $(+2)$ and $9.09 \%$ with a lot of heat $(+3)$. The temperature registers obtained in the classroom occupied by the students were from a minimum of $26.6^{\circ} \mathrm{C}$ to a maximum of $28.8^{\circ} \mathrm{C}$.

Fig. 8 demonstrates the dissatisfaction of the female students in relation to the environmental conditions: $16.67 \%$ described a comfortable thermal sensation, neither feeling hot nor cold $(0), 50 \%$ presented low heat sensation $(+1)$ and $27.78 \%$ hot $(+2)$.

The study has also been applied to rooms at G1 building in different days, showing that the major

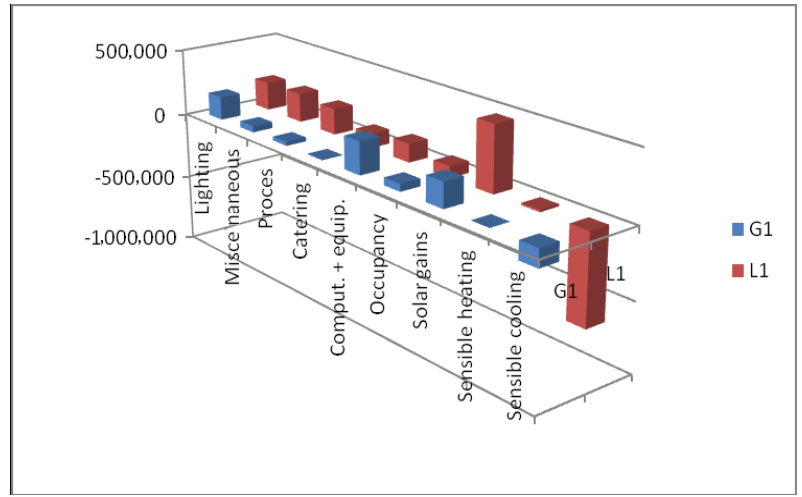

Fig. 6 Internal thermal gains of L1 and G1 [3].

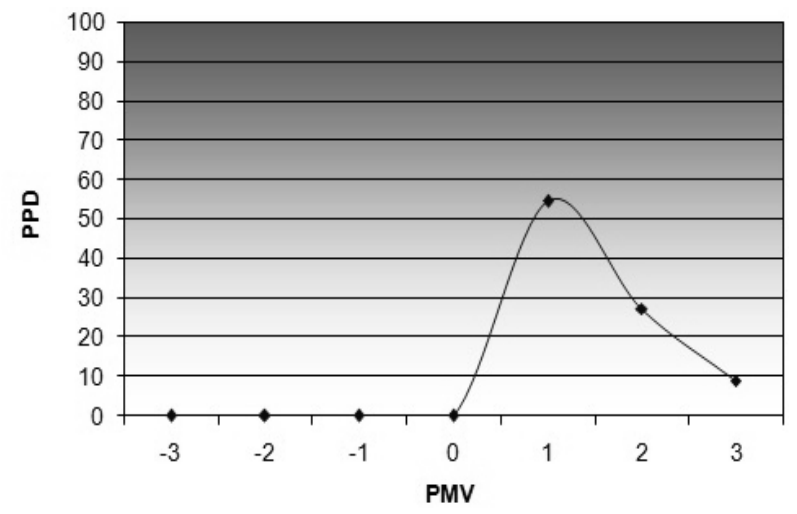

Fig. 7 PMV/PPD of male students at practice laboratory-L1, afternoon March 31, 2010.

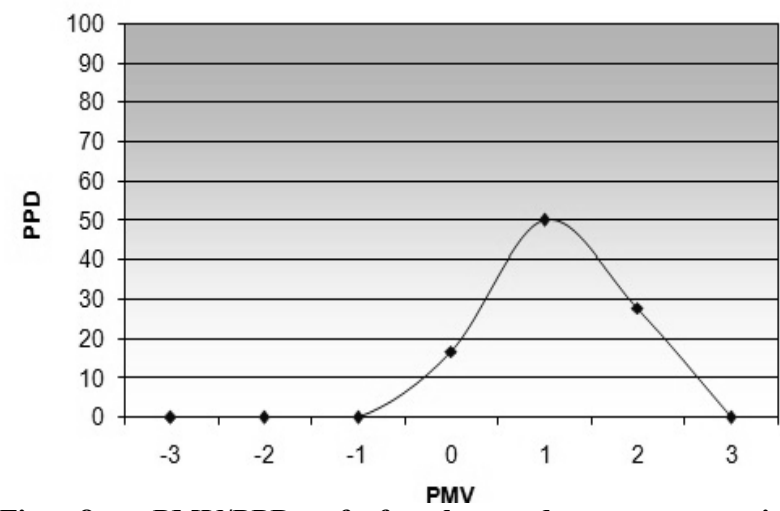

Fig. 8 PMV/PPD of female students at practice laboratory-L1, afternoon March 31, 2010.

percentage of male and female students have the same sensation to hot times, it means a little or a lot of heat $(+1$ to +3$)$.

It was observed that, even in cold conditions, the users seem to present a kind of accommodation to extremely uncomfortable situations, not only in winter but also in summer, under or above the mentioned Givoni’s limits. 


\section{Conclusions and Guidelines for Improving Eco-efficiency at UPF}

First of all, the main role of universities is remarkable, as well as their responsibility in preparing students for a more conscious and responsible professional future through knowledge and practical experience, and also to be an example of concrete actions in order to achieve the principles of a sustainable society in a collaborative and responsible way, by involving the entire university community in the imperative process of changing procedures and habits.

The research indicates that it will be possible to provide some criteria in order to improve the building stock quality by upgrading it with regard to better indoor conditions that really correspond to climate conditions (hot and humid summers and cold and damp winters), using passive strategies for heating and cooling and, at the same time, to improve the efficient and rational use of natural resources, and to reduce the environmental impact. Probably, the improvement of comfortable conditions will increase energy consumption, but there is a potential reduction of lighting and use of equipment that could minimize this impact.

It was observed that in relation to the thermal performance of the studied buildings, the energy demand has a direct influence on the architectonic typology and the openings design. The lower performance of buildings is also due to the unfavourable orientation, in particular, of the laboratories, together with a lack of ventilation. All these factors contribute to a high thermal charge for air conditioning reflecting directly by a consequential increase in energy consumption.

After this study, it was possible to suggest some guidelines to increase eco-efficiency in the building stock at UPF, both in existent buildings and those yet to be constructed.

In a general way, a revision of construction parameters for new constructions would be necessary, utilizing adequate thermal insulation coverings and the application of sustainable construction principles: for the existing buildings, a refurbishing and retrofitting program might be feasible.

The architectural design should also be revised, pointed solar orientation (especially to laboratories where the indoor conditions are more restricted), opening design that can guarantee effective reduction of solar effect besides passive heating and cooling strategies.

In order to improve projects for upgrading with the implementation of better thermal comfort conditions that corresponds to the local complex climatic conditions (hot and humid in the summer and cold and damp in the winter), it is also very important to increase use of efficient natural resources and a reduction in the associated environmental impact.

The results should be analysed, taking into consideration all the factors that present an influence on the thermal and energy output, especially concerning the use and occupation of the spaces and the efficiency of the equipment in areas such as illumination and air conditioning, or the various equipments that are part of the scope of the developing research. In this way, the systematic analysis indicates that, as a priority, to meet the real needs of the users, energy consumption should be greater because living/working conditions in both buildings are inexistent, especially during the cold periods.

The energy audit method applied to universities constitutes a valuable tool to understand the real condition of each building in order to propose a concrete plan of action and investments to achieve energy efficiency, with corresponding economic results for the entire building stock. This means achieving eco-efficiency in all its dimensions: economic, social and environmental.

Finally, it will be possible to improve the methodology as an operational tool to help in decision making during the whole life cycle, focusing the 


\section{Assessment and Guidelines to Improve Eco-efficiency and Indoor Comfort at University of Passo Fundo, Brazi}

process of design, construction and use of buildings.

In the specific case of the application to the University of Passo Fundo, the final results of the research might provide elements to propose an instrument to improve the eco-efficiency performance of the buildings stock in the campus and also to elaborate the guidelines for "Environmental Efficiency and Energy Programme" applicable to all the campuses. In this way, the use of DesignBuider simulations of real models and the refurbishment proposals show a feasible tool to compare results of performance, which should be evaluated by an economic approach, that can be helpful during the taking decision process.

\section{References}

[1] Kibert, C. J. 2005. Sustainable Construction: Green Building Design and Delivery. USA: John Wiley \& Sons.

[2] García, F. J. L., Kevany, K., and Huising, D. 2006. "Sustainability in Higher Education: What's Happening?." Journal of Cleaner Production 14 (9-11): 757-60.

[3] Frandoloso, M. A. L., Brandli, L. L., Couto, F. A., and Wildner, P. D. 2010. "The Energy and Thermal Performance of Two University Buildings in Southern Brazil with the Aim of Achieving Environmental Efficiency." In ERSCP-EMSU (The Energy and Thermal Performance of Two University Buildings in Southern Brazil with the Aim of Achieving Environmental Efficiency) 2010 Proceedings. Accessed April 21, 2012. http://repository.tudelft.nl/view/conferencepapers/uuid\%3 Abcdd6e05-89d6-45e5-ab51-890e564d83f7/.

[4] Braungart, M., and McDonough, W. 2009. Cradle to Cradle: Re-making the Way We Make Things. London: Vintage Books.

[5] Frandoloso, M. A. L., Brandli, L. L., and Dias, F. P. 2012. "Energy and Thermal Performance in Relation to the Comfort of Users of University Buildings in Southern Brazil". In IADIS International Conference on Sustainability, Technology and Education-STE2012 Proceedings, 37-44.

[6] Ferreira, A. J. D., Lopes, M. A. R., and Morais, J. P. F. 2006. "Environmental Management and Audit Schemes Implementation as an Educational Tool for Sustainability." Journal of Cleaner Production 14 (9-11): 973-82.
[7] Plazas, F. L. 2006. Sobre el Uso y la Gestión Como los Factores Principales que Determinan el Consumo de Energía en la Edificación (On the Use and Management as the Main Factors That Determine Energy Consumption in Buildings). Barcelona: UPC (Polytechnic University of Catalonia). (in Spanish)

[8] Gonzáles, M. B., Rodríguez, I., and Ruiz, G. 2006. Avaluació Energètica d'Edificis: Experiència de la UPC (Building Energy Evaluation: Experience of UPC, an Analysis Methodology). Barcelona: UPC. (in Catalan)

[9] Burgos, A. C. 2009. La Qualitat Ambiental als Edificis (The Environmental Quality of Buildings). Barcelona: Government of Catalonia. (in Catalan)

[10] DesignBuilder. 2011. "DesignBuilder EnergyPlus Simulation Documentation. DesignBuilder v3.1." Accessed December 16, 2012. http://www.designbuilder.co.uk.

[11] Fanger, P. O. 1970. Thermal Comfort: Analysis and Application in Environmental Engineering. Copenhagen: Danish Technical Press.

[12] Fanger, P. O., and Toftum, J. 2002. "Extension of the PMV Model to Non-air-Conditions Buildings in Warm Climates." Energy and Buildings 34 (6): 533-6.

[13] ASHRAE. 2004. ASHRAE Standard 55: Thermal Environmental Conditions for Human Occupancy. USA: ASHRAE.

[14] Trewartha, G. 1980. An Introduction to Climate. 5 ed.. New York: McGraw-Hill.

[15] Ligget, R., and Milne, M. 2012. "Climate Consultant 5.4 (Build 4)." Software, UCLA Energy Design Tool Group. Accessed February 7, 2013. http://www.energy-design-tools. aud.ucla.edu.

[16] ABNT (Brazilian Association of Technical Standards). 2008. NBR 15575: Edifícios Habitacionais de Até Cinco Pavimentos (Residential Buildings of Up to Five Floors). Brazil: ABNT. (in Portuguese)

[17] Givoni, B. 1992. "Comfort, Climate Analysis and Building Design Guidelines.” Energy and Buildings 18: 11-23.

[18] ISO. 2005. ISO 7730: Ergonomics of the Thermal Environment-Analytical Determination and Interpretation of Thermal Comfort Using Calculation of the PMV and PPD Indices and Local Thermal Comfort Criteria. Geneva: ISO.

[19] LabEEE-UFSC (Energy Efficiency in Buildings Laboratory, Federal University of Santa Catarina). 2008. “Analysis CST, Software. v. 2.1." LabEEE-UFSC. Accessed August 13, 2010. http://www.labeee.ufsc.br/downloads/softwares. (in Portuguese) 